\title{
CHROMATIC SUMS FOR COLORINGS AVOIDING MONOCHROMATIC SUBGRAPHS ${ }^{1}$
}

\author{
Ewa Kubicka \\ University of Louisville, USA \\ e-mail: ewa@louisville.edu \\ GrZEGORZ KUBICKI \\ University of Louisville, USA \\ University of Opole, Poland \\ e-mail: gkubicki@louisville.edu
}

AND

KAthleen A. MCKeON

Connecticut College, USA

e-mail: kamck@conncoll.edu

\begin{abstract}
Given graphs $G$ and $H$, a vertex coloring $c: V(G) \rightarrow \mathbb{N}$ is an $H$-free coloring of $G$ if no color class contains a subgraph isomorphic to $H$. The $H$-free chromatic number of $G, \chi(H, G)$, is the minimum number of colors in an $H$-free coloring of $G$. The $H$-free chromatic sum of $G, \Sigma(H, G)$, is the minimum value achieved by summing the vertex colors of each $H$-free coloring of $G$. We provide a general bound for $\Sigma(H, G)$, discuss the computational complexity of finding this parameter for different choices of $H$, and prove an exact formulas for some graphs $G$. For every integer $k$ and for every graph $H$, we construct families of graphs, $G_{k}$ with the property that $k$ more colors than $\chi(H, G)$ are required to realize $\Sigma(H, G)$ for $H$-free colorings. More complexity results and constructions of graphs requiring extra colors are given for planar and outerplanar graphs.
\end{abstract}

Keywords: coloring, sum of colors, forbidden subgraphs.

2010 Mathematics Subject Classification: 05C15.

\footnotetext{
${ }^{1}$ An extended abstract was presented at the conference: Erdős Centennial, July 1-5, 2013, Budapest [20].
} 


\section{REFERENCES}

[1] M. Albertson, R. Jamison, S. Hedetniemi and S. Locke, The subchromatic number of a graph, Discrete Math. 74 (1989) 33-49.

doi:10.1016/0012-365X(89)90196-9

[2] J. Andrews and M. Jacobson, On a generalization of chromatic number, Congr. Numer. 47 (1985) 33-48.

[3] D. Archdeacon, A note on defective colorings of graphs in surfaces, J. Graph Theory 11 (1987) $517-519$. doi:10.1002/jgt.3190110408

[4] M. Borowiecki. I. Broere, M. Frick, P. Mihók and G. Semanišin, A survey of hereditary properties of graphs, Discuss. Math. Graph Theory 17 (1997) 5-50. doi:10.7151/dmgt.1037

[5] I. Broere and M. Mynhardt, Generalized colorings of outer-planar and planar graphs, Graph Theory with Applications to Algorithms and Computer Science, Wiley, New York (1985) 151-161.

[6] I. Broere, S. Dorfing and E. Jonck, Generalized chromatic numbers and hereditary properties of graphs, Discuss. Math. Graph Theory 22 (2002) 259-270. doi:10.7151/dmgt.1174

[7] H. Broersma, F.V. Fomin, J. Kratochvil and G.J. Woeginger, Planar graph coloring avoiding monochromatic subgraphs: trees, and paths make it difficult, Algorithmica 44 (2006) 343-361. doi:10.1007/s00453-005-1176-8

[8] M.I. Burstein, The bi-colorability of planar hypergraphs, Sakharth. SSR Mecn. Akad. Moambe 78 (1975) 293-296.

[9] G. Chartrand, D. Geller and S. Hedetniemi, A generalization of the chromatic number, Proc. Cambridge Philos. Soc. 64 (1968) 265-271. doi:10.1017/S0305004100042808

[10] G. Chartrand and H. Kronk, The point-arboricity of planar graphs, J. London Math. Soc. 44 (1969) 612-616. doi:10.1112/jlms/s1-44.1.612

[11] G. Chartrand, H. Kronk and C. Wall, The point-arboricity of a graph, Israel J. Math. 6 (1968) 169-175. doi:10.1007/BF02760181

[12] L.J. Cowen, R.H. Cowen and D.R. Woodall, Defective colorings of graphs in surfaces; partitions into subgraphs of bounded valency, J. Graph Theory 10 (1986) 187-195. doi:10.1002/jgt.3190100207

[13] L.J. Cowen, W. Goddard and C.E. Jesurum, Defective colorings revisited, J. Graph Theory 24 (1997) 205-219. doi:10.1002/(SICI)1097-0118(199703)24:3〈205::AID-JGT2〉3.0.CO;2-T 
[14] K. Dargen and K. Fraughnaugh, Conditional chromatic numbers with forbidden cycles, Linear Algebra Appl. 217 (1985) 53-66.

doi:10.1016/0024-3795(94)00139-5

[15] P. Erdős, E. Kubicka and A.J. Schwenk, Graphs that require many colors to achieve their chromatic sum, Proc. Twentieth Southeastern Conference on Combinatorics, Graph Theory, and Computing 71 (1990) 17-28.

[16] W. Goddard, Acyclic colorings of planar graphs, Discrete Math. 91 (1991) 91-94. doi:10.1016/0012-365X(91)90166-Y

[17] F. Harary and K. Fraughnaugh (Jones), Conditional colorability II: bipartite variations, Congr. Numer. 50 (1985) 205-218.

[18] F. Harary and K. Fraughnaugh (Jones), Degree conditional bipartition numbers in graphs, Congr. Numer. 55 (1986) 39-50.

[19] E. Kubicka, The chromatic sums and efficient tree algorithms, Ph.D. Thesis, Western Michigan University (1989).

[20] E. Kubicka, G. Kubicki and K. McKeon, Chromatic sums for colorings avoiding monochromatic subgraphs, Electron. Notes Discrete Math. 43 (2013) 247-254. doi:10.1016/j.endm.2013.07.041

[21] E. Kubicka and A. Schwenk, Introduction to chromatic sums, Congr. Numer. 71 (1990) 7-28.

[22] K. McKeon, Generalized chromatic numbers of graphs with bipartite complements, Congr. Numer. 197 (2009) 97-105.

[23] K. McKeon and H. Pham, Generalized chromatic numbers of graphs with prescribed complements, Congr. Numer. 191 (2008) 71-79.

[24] K.S. Poh, On the linear vertex-arboricity of a planar graph, J. Graph Theory 14 (1990) 73-75. doi:10.1002/jgt.3190140108

[25] C. Thomassen, Decomposing a planar graph into degenerate graphs, J. Combin. Theory Ser. B 65 (1995) 305-314. doi:10.1006/jctb.1995.1057

Received 27 February 2013

Revised 10 November 2014

Accepted 10 November 2014 